\title{
Projections of Trends in Overweight in the Elderly Population in Germany until 2030 and International Comparison
}

\author{
Christina Westphal ${ }^{a, b} \quad$ Gabriele Doblhammer ${ }^{a, b, c}$ \\ ${ }^{a}$ Rostock Center for the Study of Demographic Change, ${ }^{b}$ Max Planck Institute for \\ Demographic Research, 'Institute for Sociology and Demography, University of Rostock, \\ Rostock, Germany
}

\section{Key Words}

Overweight · Obesity · Body mass index · Elderly population · Trends · Projections

\begin{abstract}
Background/Aims: To project the numbers of pre-obese (BMI $25-29.99 \mathrm{~kg} / \mathrm{m}^{2}$ ) and obese $\left(B M I>30 \mathrm{~kg} / \mathrm{m}^{2}\right)$ men and women aged $50+$ in Germany until 2030 and to compare our estimates with actual figures from four European countries and the USA. Estimates are based on six scenarios encompassing improvements as well as worsenings of current trends. Methods: We used pooled data from 1999 to 2009 of the German Microcensus ( $n=1,472,547$ ). Using multinomial logistic regression models we estimated age-specific probabilities of preobesity and obesity and applied them to the 12th population projection of the Federal Statistical Office. Results: We project overall increases in absolute numbers of pre-obesity ranging between 14.2 and 18.2 million. However, the prevalence of pre-obesity is likely to decrease slightly. In contrast, absolute and relative numbers of obesity are projected to increase, ranging between 7.2 and 15.8 million. The international comparison revealed that pre-obesity prevalences will remain among the highest in Germany, while obesity is projected to fall below current levels of the UK or the USA. Conclusion: Pre-obesity and, particularly, obesity are likely to become a more prominent health issue in Germany in the near future which could have large repercussions for the public health system.

(c) 2014 S. Karger $\mathrm{GmbH}$, Freiburg
\end{abstract}

\section{Introduction}

Life expectancy has increased markedly in almost all industrialized countries in recent decades. However, these increases are not inevitably healthy life years, and critics alert that gains in life expectancy might be offset by the continuous increase in the numbers of over- 
weight people [1-4]. Between 1980 and 2008, the mean BMI increased worldwide by 0.4 $\mathrm{kg} / \mathrm{m}^{2}$ for males and by $0.5 \mathrm{~kg} / \mathrm{m}^{2}$ for females per decade. The age-standardized prevalence of obesity increased simultaneously from 4.8 to $9.8 \%$ for men and from 7.9 to $13.8 \%$ for women, amounting to a total number of overweight adults (BMI $\geq 25 \mathrm{~kg} / \mathrm{m}^{2}$ ) of 1.46 billion in 2008, with about 500 million of them being obese (BMI $\geq 30 \mathrm{~kg} / \mathrm{m}^{2}$ ) [2]. Forecasts suggest that the global trend towards increases in BMI will continue in the future [5-11].

For Germany, studies on overweight (BMI $\geq 25 \mathrm{~kg} / \mathrm{m}^{2}$ ) have so far only focused on past and recent trends [12-15], finding overall rising numbers of people with excess weight. However, to our knowledge, no attempts have hitherto been made to forecast the future number of overweight people. The present study closes this gap and provides estimates of the future number of overweight people in Germany until 2030. Our estimates are based on six scenarios encompassing improvements as well as worsenings of current trends.

Like other industrialized countries, population aging is one of the major challenges Germany will have to face in the coming decades. As BMI increases with age, excess weight among the elderly has become an emerging health issue and is an important determinant of healthy aging and mortality [16-19]. Therefore, this study focuses on the future number of overweight people in the German population aged $50+$.

Germany is characterized by the 'natural experiment' of reunification and, thus, provides an interesting context for studying the long-term effects of different socioeconomic and political environments on health [20]. Ever since comparisons between East and West Germany were possible, overweight prevalences have generally been higher in the East, which is attributed to different eating patterns in both parts of the country before reunification [21-23]. To determine whether there are any long-lasting differences between the two parts of the country, we performed our analysis separately for East and West Germany.

The degree to which a population is overweight varies across countries. Prevalences are higher in the south of Europe than in the north, and they have reached alarming dimensions in the USA and the UK with about two thirds of the population being overweight $[2,16,24]$. Therefore, we compared our estimates with four other European countries, i.e. Denmark, France, Spain, and the UK, and with the USA. Since there are no international comparable estimates about the future numbers of overweight for the age of $50+$, we started from the premise that the proportion of people with excess weight in those countries has remained constant at today's level until 2030, questioning at what point in time and according to which scenario we would reach comparable levels of overweight.

\section{Material and Methods}

We used the Scientific Use File (SUF) of the German Microcensus and the 12th coordinated population projection of the Federal Statistical Office. The SUF is a 70\% subsample of the original Microcensus sample, which is provided for scientific usage without restrictions. The German Microcensus is a 1\% household sample conducted once a year since 1957 in the former German Federal Republic (GFR) and since 1991 also in East Germany. Participation in the survey is obligatory by law. Registered residents living in private households or public institutions, including foreign households, are eligible to participate. Family members of foreign armed forces and diplomatic missions are not included in the sample. The participating households are randomly selected by cluster sampling [15].

Information on overweight is included for the years 1999, 2003, 2005, and 2009 and is based on selfreported measurements on weight and height. Pooling all four waves together, the dataset included 1,472,547 individuals. We calculated BMI by dividing the weight in kilograms by the squared height in meters $\left(\mathrm{kg} / \mathrm{m}^{2}\right)$. Based on World Health Organization standards, we classified respondents with a BMI below $18.5 \mathrm{~kg} / \mathrm{m}^{2}$ as underweight, and those with a BMI between 18.5 and $24.9 \mathrm{~kg} / \mathrm{m}^{2}$ were placed in the normal weight category. We separated overweight (BMI $\geq 25 \mathrm{~kg} / \mathrm{m}^{2}$ ) into pre-obesity and obesity. Respondents with a BMI between 25 and $29.99 \mathrm{~kg} / \mathrm{m}^{2}$ were classified as pre-obese, and those with a BMI greater or equal to $30 \mathrm{~kg} / \mathrm{m}^{2}$ were 
Westphal et al:: Projections of Trends in Overweight in the Elderly Population in Germany until 2030 and International Comparison

Table 1. Age polynomials and significance levels (p-values) estimated from the multinomial regression models for males and females in East and West Germany for the year 2009 (base year)

\begin{tabular}{|c|c|c|c|c|c|c|c|c|}
\hline & \multicolumn{2}{|l|}{ East males } & \multicolumn{2}{|l|}{ West males } & \multicolumn{2}{|c|}{ East females } & \multicolumn{2}{|c|}{ West females } \\
\hline & ME & p-value & $\mathrm{ME}$ & p-value & ME & p-value & $\mathrm{ME}$ & $\mathrm{p}$-value \\
\hline \multicolumn{9}{|l|}{ Pre-obesity } \\
\hline Age & 0.065778 & 0.017 & 0.604501 & 0.000 & -0.203422 & 0.000 & 0.425622 & 0.000 \\
\hline $\mathrm{Age}^{2}$ & 0.000211 & 0.694 & -0.016362 & 0.000 & 0.005427 & 0.000 & -0.013108 & 0.000 \\
\hline $\mathrm{Age}^{3}$ & -0.000007 & 0.030 & 0.000204 & 0.000 & -0.000037 & 0.000 & 0.000188 & 0.000 \\
\hline $\mathrm{Age}^{4}$ & - & - & -0.000001 & 0.000 & - & - & -0.000001 & 0.000 \\
\hline Constant & -2.418491 & 0.000 & -8.441584 & 0.000 & 1.319046 & 0.003 & -6.076805 & 0.000 \\
\hline \multicolumn{9}{|l|}{ Obesity } \\
\hline Age & -0.014644 & 0.721 & 0.631855 & 0.000 & -0.324914 & 0.000 & 0.492229 & 0.000 \\
\hline $\mathrm{Age}^{2}$ & 0.002754 & 0.000 & -0.017640 & 0.000 & 0.008405 & 0.000 & -0.015564 & 0.000 \\
\hline $\mathrm{Age}^{3}$ & -0.000027 & 0.000 & 0.000234 & 0.000 & -0.000058 & 0.000 & 0.000230 & 0.000 \\
\hline $\mathrm{Age}^{4}$ & - & - & -0.000001 & 0.000 & - & - & -0.000001 & 0.000 \\
\hline Constant & -3.236842 & 0.000 & -10.049480 & 0.000 & 1.609855 & 0.013 & -8.031885 & 0.000 \\
\hline \multicolumn{9}{|c|}{ Underweight } \\
\hline Age & -0.051136 & 0.524 & -1.185492 & 0.000 & -0.016408 & 0.773 & -0.485339 & 0.000 \\
\hline $\mathrm{Age}^{2}$ & -0.000005 & 0.997 & 0.033167 & 0.000 & -0.001398 & 0.213 & 0.013520 & 0.000 \\
\hline $\mathrm{Age}^{3}$ & 0.000006 & 0.575 & -0.000403 & 0.000 & 0.000017 & 0.017 & -0.000173 & 0.000 \\
\hline $\mathrm{Age}^{4}$ & - & - & 0.000002 & 0.000 & - & - & 0.000001 & 0.000 \\
\hline Constant & -1.298033 & 0.303 & 12.241690 & 0.000 & -0.551933 & 0.537 & 4.476358 & 0.002 \\
\hline
\end{tabular}

ME = Marginal effects.

categorized as obese. For the final analysis, we excluded individuals who provided no or incomplete information on weight and height. The final sample size was 809,976.

The 12th population projection provides information about the development of the German population separately for East and West Germany until 2060. The present study is based on the medium variant (model 1-W1) [25].

The base year for our projections was 2009, and we distinguished between the outcome categories underweight, normal weight, pre-obesity, and obesity. We modelled the age profile of each category by estimating a polynomial in a multinomial logistic regression model (equation 1):

$$
\ln \left(\frac{p}{1-p}\right)_{i}=\alpha+\beta_{1 i} * \text { age }+\beta_{2 i} * a_{a g e}+\ldots \beta_{n i} * \operatorname{age}^{n}=Z_{i}
$$

Here, $i$ denotes the $M$ outcome categories underweight, normal weight, pre-obesity, and obesity. Age is included as a numerical variable and ranges between 25 and 85. As the fit of polynomials proved to be different, we ran separate models for males and females in East and West Germany. For East Germany, the best fit proved to be a polynomial 3rd degree, for West Germany a polynomial 4th degree. In all models normal weight served as a reference group. The estimation results are displayed in table 1.

We derived our assumptions on the trends in the four categories by estimating the time trend from the four Microcensus waves again by applying a multinomial regression model (equation 2):

$$
\ln \left(\frac{p}{1-}\right)_{i}=\alpha+\beta_{1 i} * a g e+\beta_{2 i} * a g e^{2}+\ldots \beta_{n i} * a g e^{n}+\gamma_{i j} * t_{i j}
$$

Here, $t_{i j}$ denotes the time trends for the two age groups $j \leq 70$ and $j=70+$, reflecting the average annual change in weight between 1999 and 2009. The results of equation 2 reveal a remarkable and highly significant increase in obesity (table 2), while little changed regarding pre-obesity. Looking at the trends in more detail, it appears that pre-obesity decreased among those younger than the age of 70 but increased slightly among those older than 70 years. In contrast, the risk of obesity increased significantly for both age groups as well as for males and females in both parts of the country, with stronger increases in the West. According to these trends, we would have expected to project reductions in pre-obesity but increases in obesity. 
Westphal et al.: Projections of Trends in Overweight in the Elderly Population in Germany until 2030 and International Comparison

Table 2. Marginal effects (ME) and significance levels (p-values) for the time trend 1999-2009 estimated from the multinomial regression models for males and females in East and West Germany

\begin{tabular}{|c|c|c|c|c|c|c|c|c|}
\hline & \multicolumn{2}{|l|}{ East males } & \multicolumn{2}{|c|}{ West males } & \multicolumn{2}{|c|}{ East females } & \multicolumn{2}{|c|}{ West females } \\
\hline & $\mathrm{ME}$ & p-value & $\mathrm{ME}$ & p-value & $\mathrm{ME}$ & p-value & ME & p-value \\
\hline \multicolumn{9}{|l|}{ Pre-obesity } \\
\hline$t \leq 69$ & -0.00290 & 0.208 & 0.00647 & 0.000 & -0.00968 & 0.000 & -0.00242 & 0.053 \\
\hline$t \geq 70$ & 0.01970 & 0.000 & 0.01434 & 0.000 & 0.02433 & 0.000 & 0.01600 & 0.000 \\
\hline \multicolumn{9}{|l|}{ Obesity } \\
\hline$t \leq 69$ & 0.01423 & 0.000 & 0.02990 & 0.000 & 0.00229 & 0.446 & 0.01820 & 0.000 \\
\hline$t \geq 70$ & 0.03856 & 0.000 & 0.04973 & 0.000 & 0.05550 & 0.000 & 0.04744 & 0.000 \\
\hline \multicolumn{9}{|l|}{ Underweight } \\
\hline$t \leq 69$ & -0.01704 & 0.018 & -0.01672 & 0.000 & -0.00480 & 0.363 & 0.00367 & 0.165 \\
\hline$t \geq 70$ & -0.05923 & 0.000 & -0.03038 & 0.000 & -0.01286 & 0.192 & -0.01246 & 0.015 \\
\hline
\end{tabular}

In a next step, we derived age-specific probabilities of pre-obesity and obesity until 2030 (equation 3a and $3 \mathrm{~b}$ for the reference group) by combining the age polynomial from equation 1 with the period trends from equation 2 :

$$
\begin{aligned}
& P\left(Y_{i}=m\right)=\frac{e^{Z_{i}} e^{\gamma_{i} t}}{1+\sum_{i=2}^{M} e^{Z_{i}} e^{\gamma_{i} t}} \\
& P\left(Y_{i}=1\right)=\frac{1}{1+\sum_{i=2}^{M} e^{Z_{i}} e^{\gamma_{i} t}}
\end{aligned}
$$

In the projections we developed six scenarios based upon the time trends. The basic scenario (BS) assumes that the annual weight change which we observed between 1999 and 2009 will continue in the same pace until 2030.

In two acceleration scenarios (AS) we assumed that the observed average annual weight change speeds up by $10 \%$ (AS I) or doubles (AS II). Thus, we would observe $10 \%$ more or twice as much change in overweight within 1 year than we do in the BS. In this case, the trend variables $t \leq 70$ and $t>70$ are multiplied by 1.1 or 2, respectively, and thus take the values 1.1 or 2 for the year 2010, 2.2 or 4 for the year 2011, and 23.1 or 42 for the year 2030 .

In two deceleration scenarios (DS) we assumed that the annual weight change will slow down by $10 \%$ (DS I) and by $75 \%$ (DS II), i.e., within 1 year we would observe only $90 \%$ or $25 \%$ of the annual change of the BS. The status quo scenario (SQS) assumes that the share of pre-obese and obese people in the total population will remain constant from 2010 until 2030.

Finally, to project the absolute number of pre-obese and obese people until 2030 we combined the estimated age-specific probabilities from equation $3 \mathrm{a}$ and $3 \mathrm{~b}$ with the 12th coordinated population projections for Germany.

For the European comparison of our results we referred to Andreyeva et al. [16], who provide prevalence data for pre-obese and obese people aged 50+ for a selection of European countries based on the SHARE (Survey of Health, Ageing and Retirement in Europe) base study from 2004. In order to account for the heterogeneity in pre-obesity and obesity prevalences across Europe and to represent the different European regions (Scandinavia, Central Europe, and the Mediterranean), we included Denmark, France, and Spain into our comparison. For the UK and the USA, current data on pre-obesity and obesity were only available for the age group 55+ in the case of the UKand for 60+ concerning the USA. Therefore, we also estimated pre-obesity and obesity prevalences for the total German population age of 55+ and of 60+ until 2030, and compared these estimates with figures from the UK and from the USA, respectively. Data for the UK are based on the year 2005 and were taken from the National Health Service (NHS) information center [26]. For the USA, data were taken from Flegal et al. [27] who published data on pre-obesity and obesity based on the National Health and Nutrition Examination Survey (NHANES) from 2009 to 2010. 
Westphal et al.: Projections of Trends in Overweight in the Elderly Population in Germany until 2030 and International Comparison

\section{Results}

Firstly, we present our projection results for males and females in Germany. Thereafter, we compare the forecasts for the whole of Germany with actual figures from Europe and the USA. In the presentation of the results we combine the two categories underweight and normal weight and do not further differentiate between the two. The detailed projection results are provided in the supplemental material (supplemental tables 1- 7 available at http://content.karger.com/ProdukteDB/produkte.asp?doi=358738).

Projected Number of Pre-Obese Males and Females Aged 50+ in Germany until 2030

In the year 2009 , about $48.2 \%$ of the German population aged 50 + were pre-obese, corresponding to an absolute number of 15.8 million. The prevalence among men (50.4\%) was slightly higher than among women (46.4\%). Due to the negative time trend in the past we expected that pre-obesity will decrease in the future. Our projections, however, showed that the absolute number of pre-obese persons will actually increase until 2030. This is true for all scenarios but one: Only if the negative time trend decreases twice as fast as in the past (AS II), the absolute number of pre-obese people will decrease slightly. For all other scenarios we project the numbers for pre-obesity to rise, ranging between 16.6 (AS I) and 18.2 million (SQS) in 2030. Increases are projected to peak around the year 2020 but will decrease only slightly thereafter. The reason for this lies in the changing age structure, with an increasing number of persons in age groups with high prevalences of pre-obesity, thus outweighing improvements in pre-obesity.

Trends are projected to affect males and females equally. Depending on the scenario, we project the absolute number of pre-obese men to range between 6.9 (DS II) and 8.9 million (SQS) and the number of pre-obese women between 7.3 (DS II) and 9.3 million (SQS) in 2030. Yet, at the same time the prevalence of pre-obesity will decrease slightly, ranging between 38.8 and $49.5 \%$ among men and between 36.3 and $46.3 \%$ among women.

In 2009, pre-obesity prevalences for the age of 50+ were slightly higher in the East $(49.5 \%)$ than in the West (47.8\%). This difference is projected to persist until 2030, with prevalences ranging between 40.3 and $49.6 \%$ in the East and between 36.8 and $47.4 \%$ in the West.

Projected Number of Obese Males and Females Aged 50+ in Germany until 2030

In the year $2009,18.7 \%$ of the German population aged $50+$ were obese, which corresponds to an absolute number of 6.1 million. The past shift from pre-obesity to obesity is clearly reflected in our projection results, with continuous increases in the number of obese persons, ranging between 7.2 (SQS) and 15.8 million (AS II). Prevalences are estimated to range between 18.9 and $41.7 \%$ in 2030 . Assuming that the annual weight change we observed in the past continued until 2030 (BS), the obese population in Germany would increase remarkably, i.e. by $80 \%$, until 2030 . Even if the pace of change decreased by $75 \%$ (DS II) we would expect that the number of obese people increases by $30 \%$.

Increases will be similar for men and women, with absolute numbers of obese persons ranging between 3.6 and 8 million. This equals a population share ranging between 18 and $45 \%$.

The relative change in the number of obese people aged 50+ between 2009 and 2030 is projected to be higher in West Germany, i.e., obesity increases are stronger in the West than in the East. However, prevalences are estimated to be quite similar in both parts of the country in 2030, ranging between 21.6 and $39.6 \%$ in the East and between 18.2 and $42.2 \%$ in the West. 
Westphal et al.: Projections of Trends in Overweight in the Elderly Population in Germany until 2030 and International Comparison

Fig. 1. a Projected share of the German pre-obese population aged $50+$ until 2030 and comparison with Spain, France, and Denmark. b Projected share of the German obese population aged $50+$ until 2030 and comparison with Spain, France, and Denmark. $\mathrm{DK}=$ Denmark; $\mathrm{ES}=$ Spain; $\mathrm{F}=$ France; UK = United Kingdom; USA = United States of America. $\mathrm{BS}=$ Basic scenario; $\mathrm{SQS}=$ status quo scenario; AS I = acceleration scenario I; AS II = acceleration scenario II; DS I = deceleration scenario I; DS II = deceleration scenario II.

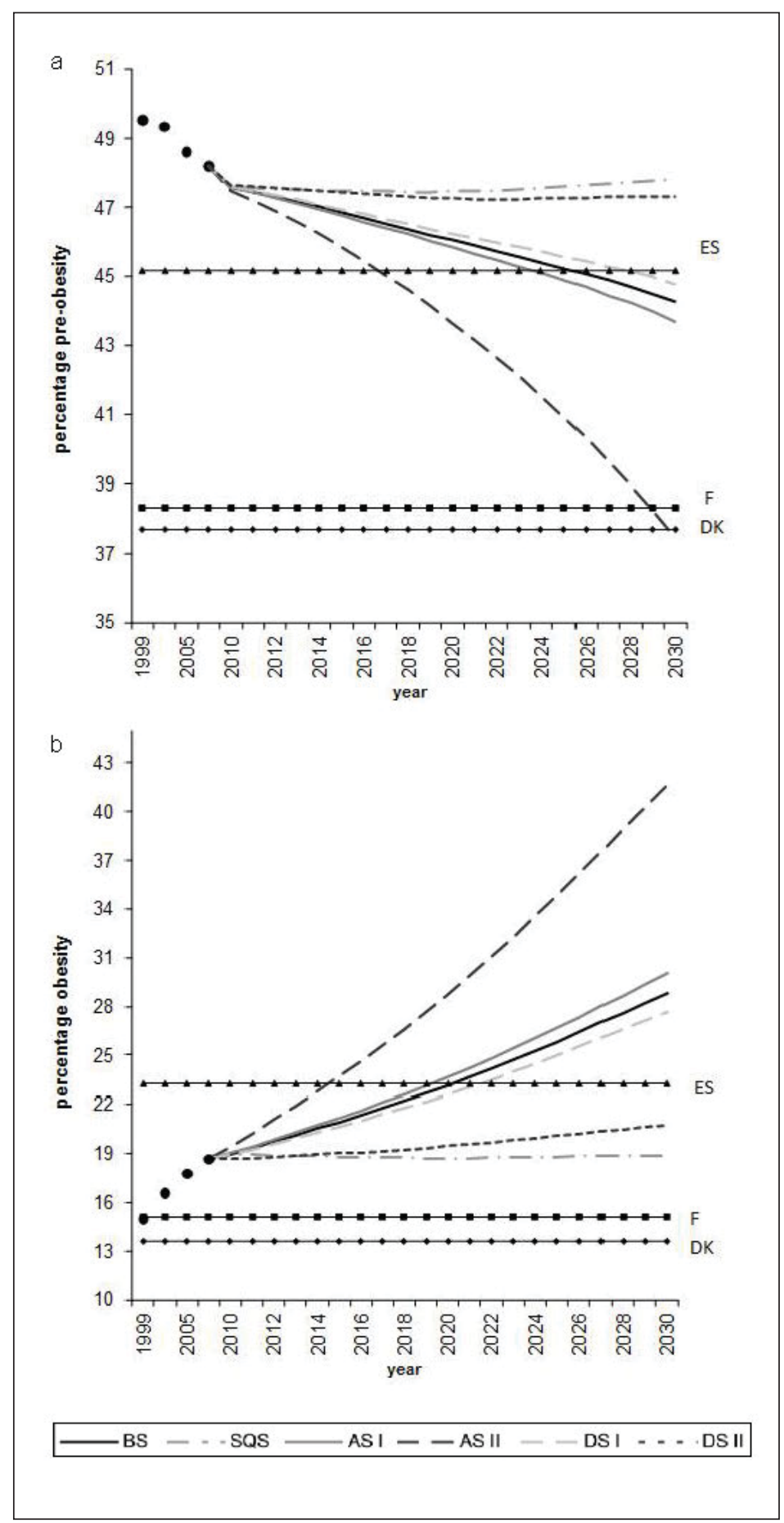

\section{International Comparison}

Overweight prevalences in Germany are among the highest in Europe [16]. In 2009, about two thirds of the total German population aged 50+ were either pre-obese $(48.2 \%)$ or obese $(18.7 \%)$. Depending on the scenario, we projected the share of pre-obese people aged $50+$ to decrease until 2030, ranging between 38 and 48\%, whereas the share of obese people will rise, ranging between $19 \%$ and $42 \%$ (fig. 1 ). 
Westphal et al.: Projections of Trends in Overweight in the Elderly Population in Germany until 2030 and International Comparison

Fig. 2. a Projected share of the German pre-obese population aged 55+ until 2030 and comparison with the UK. b Projected share of the German obese population 55+ until 2030 and comparison with the UK. DK = Denmark; $\mathrm{ES}=$ Spain; $\mathrm{F}=$ France UK = United Kingdom; USA = United States of America. BS = Basic scenario; $\mathrm{SQS}$ = status quo scenario; AS I = acceleration scenario I; AS II = acceleration scenario II; DS I = deceleration scenario I; DS II = deceleration scenario II.

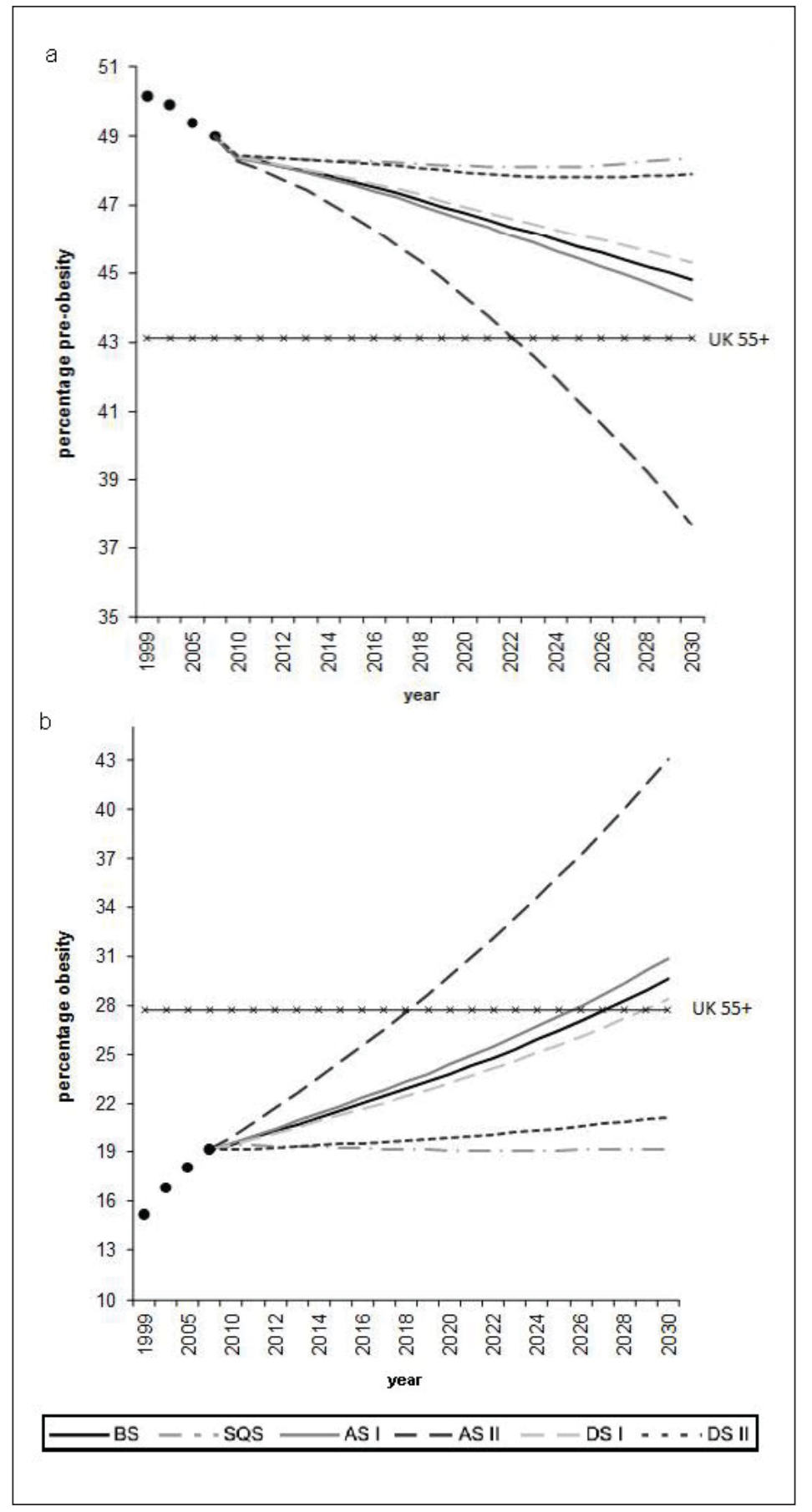

German pre-obesity prevalences for the age of 50+ are well above those of Spain (45.2\%), France (38.3\%), or Denmark (37.7\%), whereas obesity is more frequent in Spain (23.3\%) but less common in Denmark (13.6\%) or France (15.1\%). If Spanish prevalences of pre-obesity and obesity remained constant at their current levels, it would take Germany longer to reach Spain's level of pre-obesity than that of obesity. If the negative time trend in pre-obesity continued approximately with the speed of the last 10 years (AS I, BS, and DS I), it would reach the current level of Spain by the year 2025. If the time trend doubled, this would happen some 
Westphal et al.: Projections of Trends in Overweight in the Elderly Population in Germany until 2030 and International Comparison

Fig. 3. a Projected share of the German pre-obese population aged $60+$ until 2030 and comparison with the USA. b Projected share of the German obese population aged 60+ until 2030 and comparison with the USA. DK = Denmark; ES = Spain; F = France; UK = United Kingdom; USA = United States of America. BS = Basic scenario; $\mathrm{SQS}$ = status quo scenario; AS I = acceleration scenario I; AS II = acceleration scenario II; DS I = deceleration scenario I; DS II = deceleration scenario II.

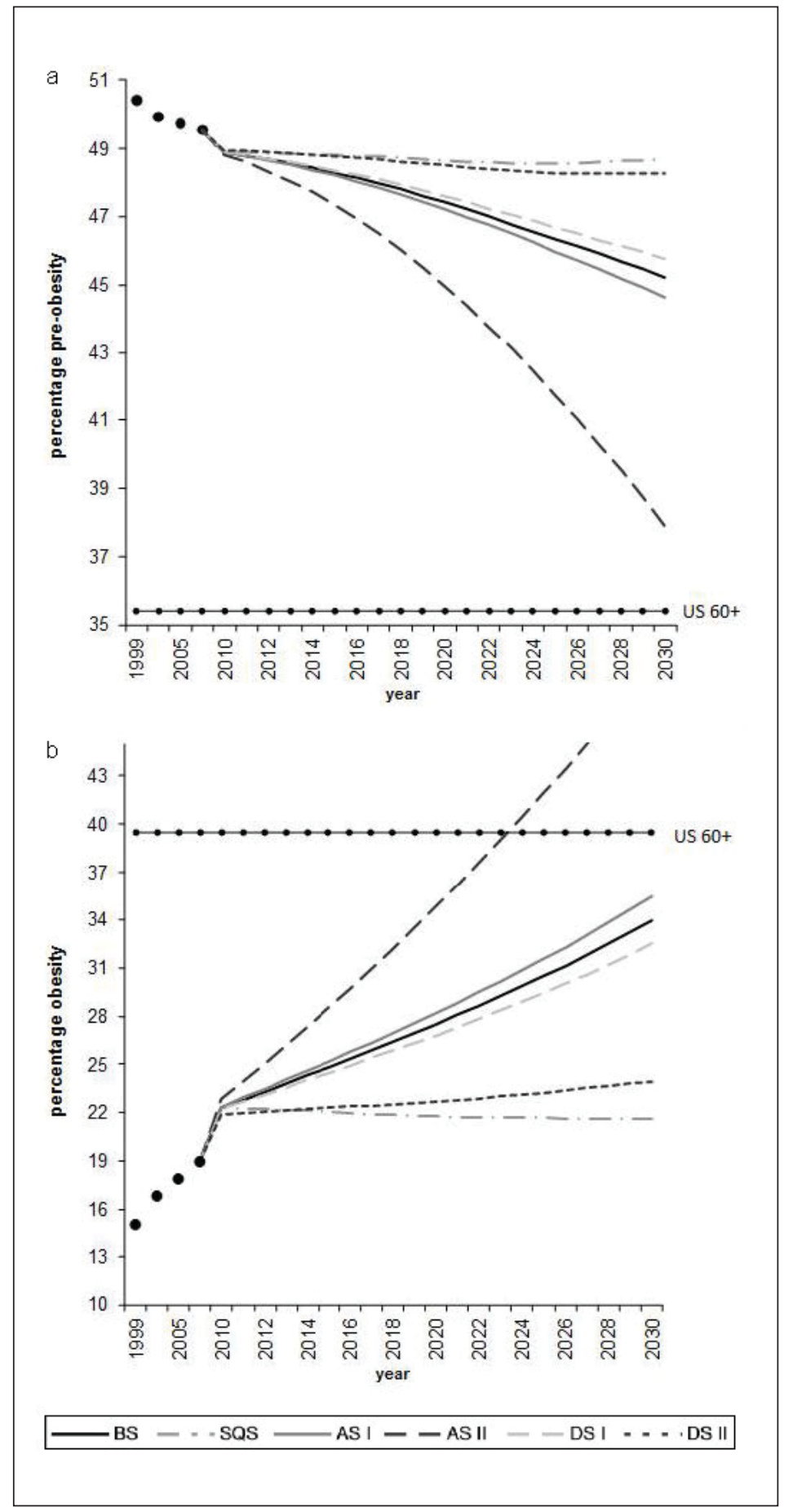

years earlier, i.e. by 2017 (fig. 1a). Turning to obesity (fig. 1b) and extrapolating past trends into the future (AS I, BS, and DS I), Germany would catch up with Spain by 2020, assuming a doubling of the time trend (AS II) by 2014. According to the other scenarios, Germany would always remain well below the Spanish obesity rates. Concerning France and Denmark (fig. 1), it seems unlikely to reach their low levels of pre-obesity and obesity. Germany would reach their pre-obesity levels by 2029 only if the time trend in pre-obesity decreased twice as fast 
Westphal et al.: Projections of Trends in Overweight in the Elderly Population in Germany until 2030 and International Comparison

as in the past. Given the past shift from pre-obesity to obesity in Germany, such a trend would, however, imply severe increases in German obesity levels. All other scenarios predict future levels of pre-obesity and obesity in Germany to remain well above the current levels of these two countries.

In the UK, the share of the pre-obese population aged $55+$ is $43.1 \%$ and therefore lower than in Germany (49\%) (fig. 2a). Continuing time trends would imply that the German population at the age of 55+ would approach the pre-obesity level of the UK by 2030 (BS, AS I, and DS I). With a doubling time trend (AS II), it would reach today's level of the UK by 2022. Otherwise, the proportion of pre-obesity would remain higher in Germany. However, the share of obese people aged 55+ is much lower in Germany (19.2\%) than in the UK (fig. 2b). In the UK, $27.7 \%$ of the population aged $55+$ were obese in 2005. If the time trend in Germany doubled, it would reach that proportion by 2018. If the time trend continued approximately with the speed of the last 10 years (BS, AS I, and DS I), it would reach similar levels not before 2025. According to the other scenarios, Germany's prevalences of obesity would always remain below the current level of the UK until 2030.

German pre-obesity prevalences at the age of $60+(49.6 \%)$ are also higher than in the USA (35.4\%) (fig. 3a) but obesity prevalences are much lower (USA 39.5\%; Germany 19\%) (fig. 3b). The share of pre-obese Germans aged 60+ would remain higher until 2030, except if the time trend doubled (AS II). In that case it would approach the pre-obesity level of today's US population aged $60+$ by 2030 . However, obesity levels will remain below the US benchmark of $39.5 \%$ until 2030 according to all scenarios but one. Only if the time trend in obesity doubled, would Germany reach today's level of the USA by 2022.

\section{Discussion}

To our knowledge, this is the first study for Germany providing estimates of the future number of pre-obese and obese people aged $50+$ until the year 2030. There has been a remarkable shift from pre-obesity to obesity between 1999 and 2009 in Germany. If trends continue unchanged, it is likely that by 2030 three quarters of the German population aged $50+$ will be diagnosed with excess weight, whereby obesity is the driving force behind these increases. Our results are in line with findings from other countries, projecting stable or slightly decreasing pre-obesity prevalences but strong increases in obesity [5-7, 9-11]. Germany is already ahead of many European countries concerning pre-obesity and obesity and is likely to remain there in the future. Although it is unlikely that it reaches obesity levels of the UK or the USA soon, obesity will presumably become a more prominent health issue in the future, which could have major repercussions for the medical and the long-term care system. As a high BMI is an established risk factor for adverse health outcomes, more obese people will result in an increasing number of obesity-related illnesses and comorbidities, especially cardiovascular diseases, which may have negative effects on healthy aging and life expectancy prospects $[1,9,16,28-38]$. However, studies have also demonstrated an 'obesity paradox', finding that obese patients with established cardiovascular conditions have better mortality outcomes and, thus, an increased survival compared to their leaner counterparts [39-41].

Our results suggest that differences in excess weight between East and West Germany are not the result of long-lasting differences in eating habits between the two parts of the country. The availability and access to dietary products have improved in the East after the reunification and are now equal in both parts of the country. Moreover, the knowledge of health risks and negative consequences of unhealthy eating patterns increased likewise in both parts of Germany. We therefore propose that 'obesogenic environments', defined as 'the 
Westphal et al.: Projections of Trends in Overweight in the Elderly Population in Germany until 2030 and International Comparison

sum of influences of the surroundings, opportunities, or conditions promoting obesity in individuals or populations' [42], are the cause for increases in excess weight in both parts of the country. As in other European countries, the availability and accessibility of high energy foods has increased in Germany over the past decades. At the same time, environments have evolved that promote sedentary lifestyles and low levels of physical activity, increasing the risk for a permanent positive energy balance. As obesity prevalences have always been higher in East Germany, West Germans may have been more vulnerable to these settings, explaining stronger increases in obesity in the West.

In general, studies attribute increases in overweight to period effects and suggest that sedentary lifestyles and unhealthy diets have contributed to a generalized increase in body weight in the whole population, regardless of age $[10,43]$. However, some studies also find that cohort effects are responsible for increases in overweight [7, 44-46]. For that reason, we ran a model that additionally accounts for cohort effects. However, this model did not alter our parameter estimates significantly, producing results that were similar to those we presented. This supports our assumption that the future numbers of pre-obese and obese people are primarily the result of period trends. Hence, if the dietary and physical activity patterns of the past continue, our projections are likely to provide a realistic range of scenarios of what Germany is to expect in the future.

The strength of our study lies in the dataset we used as it provides sufficient numbers of observations even for the highest age groups and includes the institutionalized population.

A shortcoming of this study is that we used self-reported BMI as an indicator of excess weight, which might not be the best choice because other measures such as waist-to-hip ratio, waist-to-height ratio, or waist circumference have proven to be more accurate for identifying fatness [47-49]. However, alternative measures are rarely included in mostsurveys. Moreover, subjective information on weight and height tend to underestimate BMI when compared to objective measurements [50]. Hence, we might have underestimated the number of preobese and obese people. Furthermore, we assumed that the age distribution of pre-obesity and obesity remains constant until 2030. If, however, increases in obesity were higher among younger ages than expected, we would underreport increases in obesity.

Germany, like most other nations, is likely to face a considerable increase in the numbers of obese elderly in the near future. Hence, weight education measures need to be intensified and should start at the youngest ages. Controlled weight loss should be promoted to help those with a history of obesity to lose weight.

\section{Disclosure Statement}

The authors declare no conflict of interests.

\section{References}

1 Byles J: Obesity: the new global threat to healthy ageing and longevity. Health Sociol Rev 2009;18:412-422.

-2 Finucane MM, Stevens GA, Cowan MJ, Danaei G, Lin JK, Paciorek CJ, Singh GM, Gutierrez HR, Lu Y, Bahalim AN, Farzadfar F, Riley LM, Ezzati M: National, regional and global trends in body-mass index since 1980: systematic analysis of health examination surveys and epidemiological studies with 960 country-years and 9.1 million participants. Lancet 2011;377:557-567.

-3 Olshansky JS, Passaro DJ, Hershow RC, Layden J, Carnes BA, Brody J, Hayflick L, Butler RN, Allison DB, Ludwig DS: A potential decline in life expectancy in the United States in the 21st century. N Engl J Med 2005;352: 1138-1145.

4 Stewart ST, Cutler DM, Rosen AB: Forecasting the effects of obesity and smoking on US life expectancy. N Engl J Med 2009;361:2252-2260. 
Westphal et al.: Projections of Trends in Overweight in the Elderly Population in Germany until 2030 and International Comparison

5 Basu A: Forecasting distribution of body mass index in the United States: is there more room for growth? Med Decis Making 2010;30:E1-E11.

6 Butland B, Jebb S, Kopelman P, McPherson K, Thomas S, Mardell J, Vivienne P: Foresight. Tackling Obesities: Future Choices - Project Report, ed 2. Government Office for Science, 2007. www.bis.gov.uk/foresight/ our-work/projects/published-projects/tackling-obesities/reports-and-publications.

-7 Dal Grande E, Gill T, Taylor AW, Chittleborough C: Obesity in South Australian adults - prevalence, projections and general assessment over 13 years. Aust N Z J Public Health 2005;29:343-348.

8 Kelly T, Yang W, Chen CS, Reynolds K, He J: Global burden of obesity in 2005 and projections to 2030. Int J Obes 2008;32:1431-1437.

9 Sassi F: Obesity and the Economics of Prevention. OECD - Organisation for Economic Co-operation and Development Report 2010. www.oecd.org/health/health-systems/obesityandtheeconomicsofpreventionfitnotfat. htm.

10 Sassi F, Marion D, Cecchini M, Rusticelli E: The Obesity Epidemic: Analysis of Past Trends and Projected Future Trends in Selected OECD Countries. OECD Health Working Papers No 45, 2009. www.oecd-ilibrary.org/socialissues-migration-health/the-obesity-epidemic-analysis-of-past-and-projected-future-trends-in-selected-oecdcountries_225215402672.

$\checkmark 11$ Schneider H, Dietrich ES, Venetz WP: Trends and stabilization up to 2022 in overweight and obesity in Switzerland; comparison to France, UK, US and Australia. Int J Environ Res Public Health 2010;7:460-472.

$\checkmark 12$ Helmert U, Strube H: Die Entwicklung der Adipositas in Deutschland im Zeitraum von 1985 bis 2002. Gesundheitswesen 2004;66:409-415.

13 Mensink GBM, Lampert T, Bergmann E: Übergewicht und Adipositas in Deutschland 1984-2003. Bundesgesundheitsbl Gesundheitsforsch Gesundheitsschutz 2005;48:1348-1356.

14 Robert Koch-Institut: KiGGS - Studie zur Gesundheit von Kindern und Jugendlichen in Deutschland. 2006. www.kiggs-studie.de/english/home.html.

15 Statistisches Bundesamt: Mikrozensus - Fragen zur Gesundheit. Körpermaße der Bevölkerung 2009. 2010. www.gbe-bund.de/stichworte/MIKROZENSUS.html.

-16 Andreyeva T, Michaud PC, van Soest A: Obesity and health in Europeans aged 50 years and older. Public Health 2007;121:497-509.

17 DeCaria JE, Sharp C, Petrella RJ: Scoping review report: obesity in older adults. Int J Obes 2012;36:1141-1150.

-18 Ziegler U, Doblhammer G: Projections of the number of people with dementia in Germany 2002 through 2047; in Doblhammer G, Scholz R (eds): Ageing, Care Need and Quality of Life: The Perspective of Care Givers and People in Need of Care. Wiesbaden, VS Verlag für Sozialwissenschaften, 2010, pp 94-111.

19 Mathus-Vliegen EMH, Basdevant A, Finer N, Hainer V, Hauner H, Micic D, Maislos M, Roman G, Schutz Y, Tsigos C, Toplak H, Yumuk V, Zahorska-Markiewicz B: Prevalence, pathophysiology, health consequences and treatment options of obesity in the elderly: a guideline. Obes Facts 2012;5:460-483.

20 Westphal C, Doblhammer G: The diffusion of smoking in East and West Germany: Smoking patterns by birth year. Population-E 2012;67:653-670.

-21 Heinemann L, Helmert U, Classen E, Greiser E: Social gradient of CVD risk in Germany before/after unification. Rev Environ Health 1996;11:7-14.

22 Heinemann LAJ, Greiser EM: Blood pressure, hypertension, and other risk factors in East and West Germany. Ann Epidemiol 1993;3:S90-S95.

23 Thiel C, Heinemann L: Nutritional behaviour differences in Germany. Rev Environ Health 1996;11:35-40.

24 Berghöfer A, Pischon T, Reinold T, Apovian CM, Sharma AM, Willich SN: Obesity prevalence from a European perspective: a systematic review. BMC Public Health 2008;8:200.

25 Statistisches Bundesamt: Bevölkerung Deutschlands bis 2060. 12. koordinierte Bevölkerungsvorausberechnung. Wiesbaden, Statistisches Bundesamt, 2009.

26 Mills TC: Forecasting obesity trends in England. J R Statist Soc 2009;172:107-117.

-27 Flegal KM, Carroll MD, Kit BK, Ogden CL: Prevalence of obesity and trends in the distribution of body mass index among US adults, 1999-2010. JAMA 2012;307:491-497.

28 Allender S, Rayner M: The burden of overweight and obesity-related ill health in the UK. Obes Rev 2007;8: 467-473.

29 Arena R, Lavie CJ: The obesity paradox and outcome in heart failure: is excess bodyweight truly protective? Future Cardiol 2010;6:1-6.

-30 Bleich S, Cutler DM, Murray C, Adams A: Why is the developed world obese? Annu Rev Public Health 2008;29: 273-295.

31 Christensen K, Doblhammer G, Rau R, Vaupel JW: Ageing populations: the challenges ahead. Lancet 2009;374: 1196-1208.

32 Cutler DM, Glaeser EL, Rosen AB: Is the US population behaving healthier? NBER Conference on Retirement Research. Cambridge, MA, National Bureau of Economic Research, 2007.

33 Doblhammer G, Hoffmann R, Muth E, Nusselder W: The effect of sex, obesity and smoking on health transitions: a statistical meta-analysis; in Doblhammer G, Scholz R (eds): Ageing, Care Need and Quality of Life. Wiesbaden, VS Verlag für Sozialwissenschaften, 2010, pp 114-142.

-34 Doblhammer G, Hoffmann R, Muth E, Westphal C, Kruse A: A systematic literature review of studies analyzing the effects of sex, age, education, marital status, obesity, and smoking on health transitions. Demogr Res 2009; 20:37-64. 
Westphal et al.: Projections of Trends in Overweight in the Elderly Population in Germany until 2030 and International Comparison

-35 Flegal KM, Graubard BI, Williamson DF, Gail MH: Excess deaths associated with underweight, overweight and obesity. JAMA 2005;293:1861-1867.

36 Konnopka A, Bödemann M, König H-H: Health burden and costs of obesity and overweight in Germany. Eur J Health Econ 2011;12:345-352.

37 Vartanian LR: Disgust and perceived control in attitudes towards obese people. Int J Obes 2010;34:1-6.

-38 Wilborn C, Beckham J, Campbell B, Harvey T, Galbreath M, La Bounty P, Nassar E, Wisman J, Kreider R: Obesity, prevalence, theories, medical consequences, management and research directions. J Int Soc Sports Nutr 2005; 2:4-31.

-39 Doehner W, Schenkel J, Anker SD, Springer J, Audebert H: Overweight and obesity are associated with improved survival, functional outcome, and stroke recurrence after acute stroke or transient ischaemic attack: obervations from the TEMPiS trial. Eur Heart J 2012;34:268-277.

40 Habbu A, Lakkis NM, Dokainish H: The obesity paradox: fact or fiction? Am J Cardiol 2006;98:944-948.

41 Lavie CJ, Alpert MA, Arena R, Mehra MR, Milani RV, Ventura HO: Impact of obesity and the obesity paradox on prevalence and prognosis in heart failure. JACC Heart Fail 2013;1:93-102.

42 Swinburn B, Egger G, Raza F: Dissecting obesogenic environments: the development and application of a framework for identifying and prioritizing environmental interventions for obesity. Prev Med 1999;29:563570.

43 Seidell JC, Flegal KM: Assessing obesity: classification and epidemiology. Br Med Bull 1997;53:238-252.

44 Juhaeri JS, Jones DW, Donna A: Associations of aging and birth cohort with body mass index in a biethnic cohort. Obes Res 2003;11:426-432.

45 Lahti-Koski M, Jousilahti P, Pietinen P: Secular trends in body mass index by birth cohort in Eastern Finland from 1972 to 1997. Int J Obes 2001;25:727-734.

46 Reither EN, Hauser RM, Yang Y: Do birth cohorts matter? Age-period-cohort analyses of the obesity epidemic in the United States. Soc Sci Med 2009;69:1439-1448.

47 Burkhauser RV, Cawley J: Beyond BMI: the value of more accurate measures of fatness and obesity in social science research. J Health Econ 2008;27:519-529.

48 Heitmann BL, Frederiksen P, Lissner L: Hip circumference and cardivascular morbidity and mortality in men and women. Obes Res 2004;12:482-487.

49 Schneider HJ, Friedrich N, Klotsche J, Pieper L, Nauck M, John U, Dörr M, Stephan F, Lehnert H, Pittrow D, Silber S, Völzke H, Stalla GK, Wallaschofski H, Wittchen H-U: The predictive value of different measures of obesity for incident cardiovascular events and mortality. J Clin Endocrinol Metab 2010;95:1777-1785.

-50 Glaesmer H, Brähler E: Schätzung der Prävalenz von Übergewicht und Adipositas auf der Grundlage subjektiver Daten zum Body-Mass-Index. Gesundheitswesen 2002;64:133-138. 